\title{
O significado do declínio organizacional: o caso UFN III
}

\author{
The meaning of the organizational decline: the NFU III case
}

\section{El significado del declinio organizacional: el caso UFN III}

\author{
Eveli Freire Vasconcelos ${ }^{1}$ \\ Antonio Virgílio Bittencourt Bastos ${ }^{2}$
}

Recebido em 07/11/2018; revisado e aprovado em 1이이리 2019; aceito em 08/04/2019

DOI: http://dx.doi.org/10.20435/inter.v20i4.2221

\begin{abstract}
Resumo: Esta pesquisa buscou descrever as significações das experiências de ex-funcionários da construção da Unidade de Fertilizantes Nitrogenados III em Três Lagoas, MS, a partir do fenômeno de declínio organizacional. A metodologia consistiu de análise documental e entrevistas. Nos resultados organizaram-se as ideias centrais do conteúdo dos relatos em mapas coletivos que representam o esquema cognitivo do declínio organizacional. As conclusões do estudo evidenciam que o fenômeno ainda é muito pouco explorado, especialmente tendo o indivíduo como unidade de análise.
\end{abstract}

Palavras-chave: declínio organizacional; experiência dos trabalhadores; Unidade de Fertilizantes Nitrogenados III.

Abstract: This research aimed to describe the meaning of experiences of former employees of the construction of the Nitrogenated Fertilizer Unit III in Três Lagoas, MS, through the organizational decline phenomenon. The methodology consisted in documentary analysis and interviews. The results organized the central ideas in cognitive maps of each of the six participants that represent the schema of the organizational decline. The conclusions of the study show that the organizational decline is still a phenomenon very little explored, especially having the individual as the unit of analysis.

Keywords: organizational decline; employee experience; Nitrogenated Fertilizer Unit III.

Resumen: Esta investigación buscó describir el significado de las experiencias de ex funcionarios de la construcción de la Unidad de Fertilizantes Nitrogenados III, em Três Lagos, MS, desde el fenomeno del deterioro organizacional. La metodología consistió en análisis documental y entrevistas. En los resultados se organizaron las ideas centrales del contenido de los relatos en mapas cognitivos de cada un de los seis participantes que representan el esquema del deterioro organizacional. Las conclusiones del estudio mostró que el deterioro organizacional, todavia es um fenomeno muy poco investigado, especialmente teniendo el individuo como unidad de analisis.

Palabras-clave: declinación organizacional; experiencia del empleado; Unidad de Fertilizantes Nitrogenados III.

\section{INTRODUÇÃO}

$\mathrm{Na}$ atualidade, temos assistido a várias situações que incidem de forma substancial nas empresas e, por consequência, nos trabalhadores. As ocorrências têm sido caracterizadas por sua velocidade e excepcionalidade, atingindo segmentos e organizações nunca antes ameaçadas, como no caso da Petrobrás. Essas mudanças têm repercutido significativamente na economia do Brasil, com sérias consequências sociais, mas pouco se sabe a respeito da dinâmica intrínseca dos trabalhadores que viveram essa experiência de declínio organizacional. Nesse sentido, o presente estudo explora cognições que estruturam o esquema cognitivo dos atores sobre o fenômeno de declínio e como este se associa a comportamentos futuros de pós-declínio.

O problema central proposto neste estudo relaciona-se aos elementos da estrutura cognitiva apresentada por atores quanto à experiência de trabalho na Unidade de Fertilizantes Nitrogenados III (UFN III), seu ingresso, declínio, desligamento e pós-desligamento. Dessa forma, o estudo propôs conhecer como o trabalhador compreende e avalia a experiência na UFN III e

\footnotetext{
${ }^{1}$ Universidade Católica Dom Bosco (UCDB), Campo Grande, MS, Brasil.

${ }^{2}$ Universidade Federal da Bahia (UFBA), Salvador, Bahia, Brasil.
} 
o fenômeno de declínio organizacional, identificando os elementos constitutivos do esquema associado à experiência. Sabe-se que a forma como os atores estruturam seu conhecimento sobre a realidade irá influenciar seu comportamento, mas ainda é escassa a compreensão sobre a dinâmica intrínseca desses processos internos, principalmente que venham empiricamente esclarecer aquilo que já está consolidado (BASTOS; JANISSECK, 2014). Assim, o presente artigo é um recorte de um "estudo multicasos" que prioriza neste trabalho a forma coletiva da experiência a partir da perspectiva integrativa dos atores.

\section{A COGNIÇÃO NO ESTUDO DO DECLÍNIO ORGANIZACIONAL}

A perspectiva cognitiva se apropria do contexto organizacional a partir de um conjunto de processos sociais que asseguram o modo como são construídos e compartilhados os conhecimentos, as crenças e as atitudes em relação aos outros e como são equacionados os diferentes fatores presentes na situação de trabalho (VASCONCELOS; COSTA, 2016). Ao ressaltar os indivíduos e suas interações como estruturas das organizações, Bastos et al. (2014) destacam que isso se deve à ideia de que a forma pela qual os indivíduos organizam e processam o seu pensamento influencia a ação individual e a partilha desse pensamento/ação entre os membros da organização. Nobre, Tobias e Walker (2011, p. 415) "propõe[m] que a cognição envolve processos e representações capazes de proporcionar inteligência, autonomia, aprendizagem e gestão do conhecimento aos indivíduos, grupos e organizações" e nesse sentido, a marcam como fundamento da habilidade organizacional.

Segundo Mohammed, Klimoski e Rentsch Jr. (2000), a abordagem cognitiva, assim como a noção de cognição, tem recebido maior atenção na literatura organizacional, pois a construção de um modelo mental compartilhado é um objeto de estudo de grande relevância. Nessa direção, conhecer e compreender o conjunto de ideias, ou elementos interligados a determinada pessoa ou a determinado grupo, é uma forma de entender como experienciam o mundo e se comportam diante dos acontecimentos (RIEG; ARAUJO FILHO, 2003). Para Axelrod (2014), a teoria dos esquemas pode constituir uma ferramenta rica para examinar complexos processos nas organizações. Os atores, especialmente aqueles que possuem o poder formal de moldar as estruturas organizacionais, são portadores de amplos e complexos esquemas cognitivos acerca de como deve ser e funcionar uma organização, os esquemas determinam a interpretação cognitiva de um indivíduo em situações sociais.

Recentes avanços tecnológicos permitem que os cientistas sociais explorem mais plenamente as nuances do processamento cognitivo, o que torna a Ciência Cognitiva uma abordagem indicada para a compreensão de como os atores organizacionais estruturam e organizam seu conhecimento, especialmente em momentos de crise, como o que vive o Brasil, onde o cenário atual demanda um balanço crítico dos impactos psicossociais dos problemas socioeconômicos, principalmente no mundo do trabalho. Além disso, abraçar abordagens menos tradicionais, como a cognitiva, aumenta a capacidade de avaliar a formação e difusão das representações coletivas compartilhadas dentro e fora das organizações (HOWARD; RENFROW, 2003).

Os autores alertam sobre as novas situações, nunca antes vividas, ou situações de alto esforço, em que os resultados são inesperados ou particularmente negativos, como a falência, decadência ou até o declínio das organizações. No entanto pouco tem sido pesquisado quanto às respostas cognitivas a um ambiente de trabalho incerto ou inseguro, o que, para Eggers e Kaplan (2009), desperta ainda mais o interesse por estudos sistemáticos sobre esses fenômenos. 
Para Carvalho (2013), o declínio organizacional pode ser reflexo da estagnação ou da redução, podendo ser originária do mercado, do aumento da competição, da não adaptação a um nicho ou clientes da própria organização ou da ausência de adaptação à mudança organizacional. Segundo a autora, essa falta de adaptação ao ambiente é uma falha grave, uma vez que o ambiente influencia muito nas tomadas de decisões da organização.

Entrar em declínio não necessariamente significa falir ou paralisar as atividades, sendo que, em todas as fases, é possível retomar o desempenho; apenas na última (fase de dissolução) a recuperação não é mais eficaz (SALLES, 2015). Na realidade, não se entende ainda, de fato, o que leva as empresas a declinarem, e isso pode estar relacionado à falta de estudos empíricos (SERRA; FERREIRA; ALMEIDA, 2013). A escassez de pesquisa empírica sobre declínio ainda é dominante e típica de áreas emergentes, especialmente na realidade brasileira. O tema tem ampla gama de possibilidades para estudo, tanto em sua singularidade como causa, quanto em seu processo e suas consequências. Assim, o presente trabalho destaca a posição dos atores organizacionais diante do fenômeno de declínio e destaca a insegurança pela ameaça de desemprego vivida durante o período.

Assim, parece importante nos atentarmos para a maneira como esses sujeitos concebem e explicam a experiência de declínio organizacional; mapear os esquemas dos atores permite a compreensão do fenômeno estudado e pode contribuir para obter uma melhor apreensão das crenças e atitudes relativas ao pós-declínio, "os esquemas são estruturas cognitivas que dão sentido à experiência” (LABIANCA; GRAY; BRASS, 2000, p. 235).

\section{MÉTODO}

Quanto ao propósito de alcance da pesquisa, esta investigação se enquadra como descritiva e exploratória, o trabalho propõe um corte transversal, com coleta de dados recorrentes, envolvendo a realização de entrevistas semiestruturadas e consulta a documentos, sem acompanhamento das variáveis ao longo do tempo. No que tange ao ambiente, caracteriza-se como pesquisa de campo. A empresa foi tratada como unidade de amostra e a unidade de análise serão os trabalhadores da construção da UFN III, vinculados legalmente ao consórcio ou à empresa líder do consórcio e se caracteriza como estudo de casos.

\section{PARTICIPANTES}

Foram entrevistados 6 trabalhadores (de cargos distintos, sendo 5 vinculados ao consórcio e 1 deles à Galvão- empresa líder do consórcio), o que permitiu a construção de estudos de casos com procedimentos qualitativos de coleta e análise de dados

Os atores tinham cargos distintos e ocupavam posições diferenciadas na estrutura organizacional de construção do projeto UFN III: o participante A foi Gerente de Produção; o B, Coordenador de Sistema de Gestão Integrada; o C, Técnico de Documentação; o D, Assistente de Engenharia; o E, Carpinteiro; e o F, Ajudante.

A UFN III, como empreendimento de relevância nacional, atraiu trabalhadores de outras cidades de Mato Grosso do Sul, como também mão de obra migratória de outros Estados. Com a paralisação de sua construção, muitos trabalhadores voltaram às suas cidades de origem, e o convite para a participação nesta pesquisa precisou adaptar-se a essa situação, de modo a definir a realização da pesquisa por e-mail e/ou redes sociais, além da possibilidade da entrevista 
presencial. No contexto contemporâneo, as redes sociais podem ser um recurso eficaz de acesso aos participantes de uma investigação. Segundo Breakwell et al. (2010), as pesquisas por e-mail já são usualmente utilizadas com questionários e planos de entrevistas.

\section{COLETA DE DADOS: ENTREVISTA}

Segundo Wildman, Salas e Scott (2013), quando se pretende pesquisar cognição, a primeira decisão refere-se à abordagem utilizada para reunir os dados que serão avaliados. Nesse caso, a entrevista foi estruturada com objetivo de gerar informações sobre dados sociodemográficos e ocupacionais dos participantes. Em seguida, o instrumento retomou o início e o desenvolvimento das atividades laborais na UFN III; os problemas que marcaram o declínio organizacional (mencionado na entrevista como "problemas"); a paralisação definitiva da construção da UFN III e seus impactos; em sua quarta parte, a entrevista abordou o mercado de trabalho atual e futuro, buscando também reconhecer as expectativas dos trabalhadores; por último e em outro momento, a pesquisadora retomou o contato e indagou ao participante o que significou para ele (pessoal e profissionalmente) ter passado por essa experiência de trabalho na UFN III.

\subsection{Análise dos dados}

A análise dos dados também foi realizada de acordo com o tipo de dado gerado pelos instrumentos de pesquisa. Assim, o conteúdo da pesquisa documental foi estruturado para apresentação do projeto organizacional UFN III, bem como a descrição de seu histórico desde a constituição até o declínio.

Na construção dos mapas coletivos sobre as diversas etapas da experiência na UFN III, buscou-se a partir do ATLAS.TI (ATLAS.TI Scientific Software Development GMBH, Berlim, Alemanha) apurar a descrição analítica já realizada pelo pesquisador com a construção de categorias a partir dos significados comuns dos trechos de entrevista. O ATLAS.TI é um software que permite a análise qualitativa de dados, com melhoria da qualidade da investigação, pelo rigor.

O núcleo do mapa é a categoria que surge a partir das falas do grupo sobre cada um dos momentos de experiência na UFN III, formado por elementos que representam (definem) o estímulo (temática) para apresentação dos esquemas (significados). As setas pretas do mapa fazem a relação semântica entre os conteúdos e o núcleo de significação do mapa coletivo; e as setas vermelhas apresentam a articulação dos conteúdos por ator e entre os atores, sendo destacado em alaranjado o conteúdo partilhado. Os mapas utilizados neste trabalho são mapas de identidade, capazes de identificar os blocos conceituais básicos com que os atores trabalham (RIOS et al. 2009).

Para a realização da presente pesquisa, foram seguidas todas as recomendações relativas à ética na pesquisa com seres humanos das Resoluções n. 196/96 e n. 466/12 do Conselho Nacional de Saúde.

\section{RESULTADO E DISCUSSÃO}

O Brasil está pronto para se tornar o principal fornecedor de produtos agrícolas, capaz de atender à crescente demanda mundial. O país reúne as maiores áreas agricultoras disponíveis e, com elevado potencial, o setor vem crescendo significativamente nos últimos 20 anos, bem 
como expandindo e consolidando suas fronteiras agrícolas. No entanto a Organização das Nações Unidas para Alimentação e Agricultura (OCDE, 2015) argumenta que ainda registra grande dependência externa de fertilizantes, o que se apresenta como prejudicial ao desenvolvimento do fornecimento agrícola.

\section{A UFN III}

Dessa forma, a implantação da UFN III teria como finalidade produzir fertilizantes nitrogenados, que são um dos principais insumos para o crescimento e melhoria da produtividade agrícola nacional, o que ajudaria a reduzir a dependência das importações de fertilizantes, uma vez que, atualmente, o Brasil importa cerca de $70 \%$ do fertilizante que consome.

A obra da UFN III, vinculada ao Programa de Aceleração do Crescimento (PAC) do Governo Federal, localizava-se em Três Lagoas, Mato Grosso do Sul, no Distrito Industrial Córrego da Moeda. O empreendimento tinha como órgão responsável o Ministério de Minas e Energia (MME) e como executora a Petrobrás. Seu objetivo era diminuir, por meio de produção de ureia, amônia e gás natural, a importação desses elementos (PROMINP, [s.d.]) para produção de fertilizantes. A obra recebeu, entre os anos de 2011 e 2014, investimentos no valor de R\$3.847.600.000,00; e, após 2014, de $R \$ 596.960 .000,00$,

Os impactos esperados e publicados nos relatórios iniciais da Petrobrás previam alteração mediana nos fatores ambientais, mas se ressaltava o caráter estratégico de alguns setores da economia. A construção da UFN III e sua operação trariam ao Estado um alto impacto, especialmente pela absorção de sua mão de obra.

Entretanto, em julho de 2014, os jornais noticiavam a solicitação de 133 empresários da cidade que pediam apoio à Câmara de Vereadores, pois, devido à inadimplência das empresas do consórcio, corriam risco de falência.

No dia 19 de dezembro de 2014, a Petrobrás informou pelos jornais a rescisão do contrato para construção e montagem da UFN III em razão do descumprimento do contrato pelo consórcio, com consequente paralisação total da construção.

\section{UMA VISÃO DO PROCESSO: INTEGRANDO A PERSPECTIVA DOS ATORES}

Esperou-se encontrar uma diferenciação nos elementos que compõem o esquema cognitivo construído pelos atores, mas também similaridades, próprias da experiência de declínio. Isso envolveu a consideração de que haveria diferenças na forma como interpretam e constroem sentido da experiência, mas a suposição de também encontrar elementos partilhados. Dessa maneira, optou-se pelo mapeamento, que possibilitou a estruturação de uma matriz grupal do conteúdo, capaz de evidenciar os elementos constitutivos do esquema; assim, explorou-se o significado atribuído à experiência profissional, mas apresentam-se somente os mapas coletivos do declínio.

\subsection{Declínio organizacional}

Apesar de alguns estudos avaliarem o declínio organizacional sob um foco específico, Salles (2015) especifica fatores internos e externos como causas às dificuldades em se controlar as mudanças externas e como estas podem ser agentes causadores de declínio. Compreendendo, 
portanto, o declínio como um conceito que envolve causas múltiplas, apresenta-se a percepção dos autores.

Figura 1 - Esquema de causas do declínio organizacional

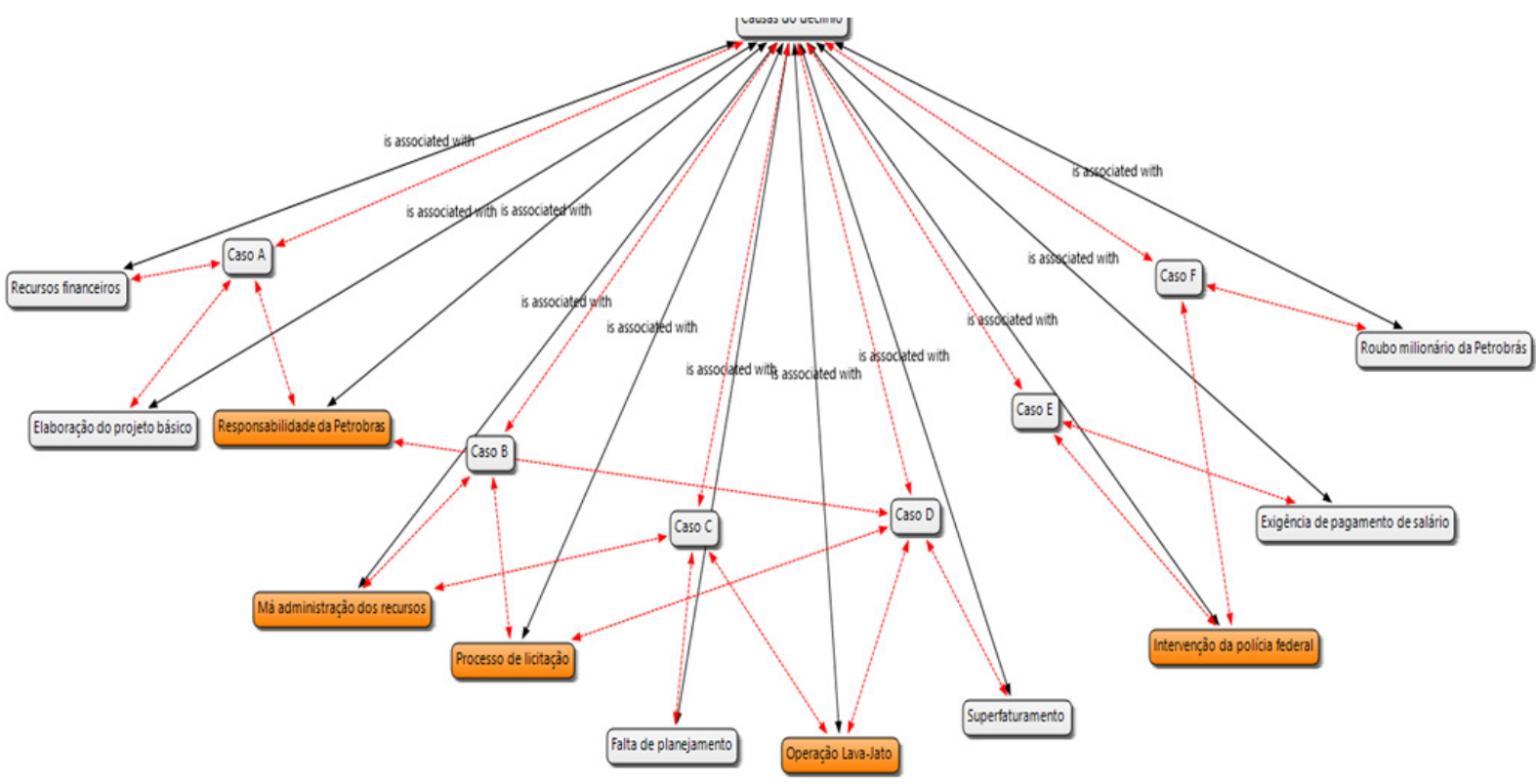

Fonte: Vasconcelos (2016).

Nota-se que os fatores associados às causas se relacionam ao setor de atividade e à Petrobrás, tanto no que se refere à elaboração do projeto básico, processo de licitação, falta de planejamento (A, B, C) quanto à sua situação atual e a operação Lava Jato (C, D, E e F). Isso caracteriza a relevância dos fatores ambientais, assim como a importância da estatal como causa do declínio para os atores, que destacam em seu discurso conteúdos sobre os fatores econômicos do país, bem como a crise no setor, relacionados à Petrobrás. Assim, sugere que a resposta de continuidade do projeto organizacional UFN III também tende a ser determinada pela quantidade e qualidade das mudanças ambientais.

Os fatores contextuais, os ambientes políticos, legais e econômicos associam-se ao declínio $(F)$, relatam o roubo milionário (D), expressam seu conhecimento sobre o superfaturamento no projeto. Os relatos mostram que as características definidoras das causas do declínio, segundo a visão dos atores, além das variáveis já apontadas, são aquelas próprias dos fatores administrativos e de natureza política.

Os dados evidenciam que os atores expressam percepções associadas às causas. Para Souza (2007, p. 54), "implica dizer que não é uma perfeita concordância, mas que eles encontram certa similaridade na forma como processam e avaliam a informação, ou seja, apresentam uma consensualidade cognitiva". A seguir, a limitação de recursos surge como o maior indicador do declínio da UFN III. 
Figura 2 - Esquema de evidências do declínio organizacional

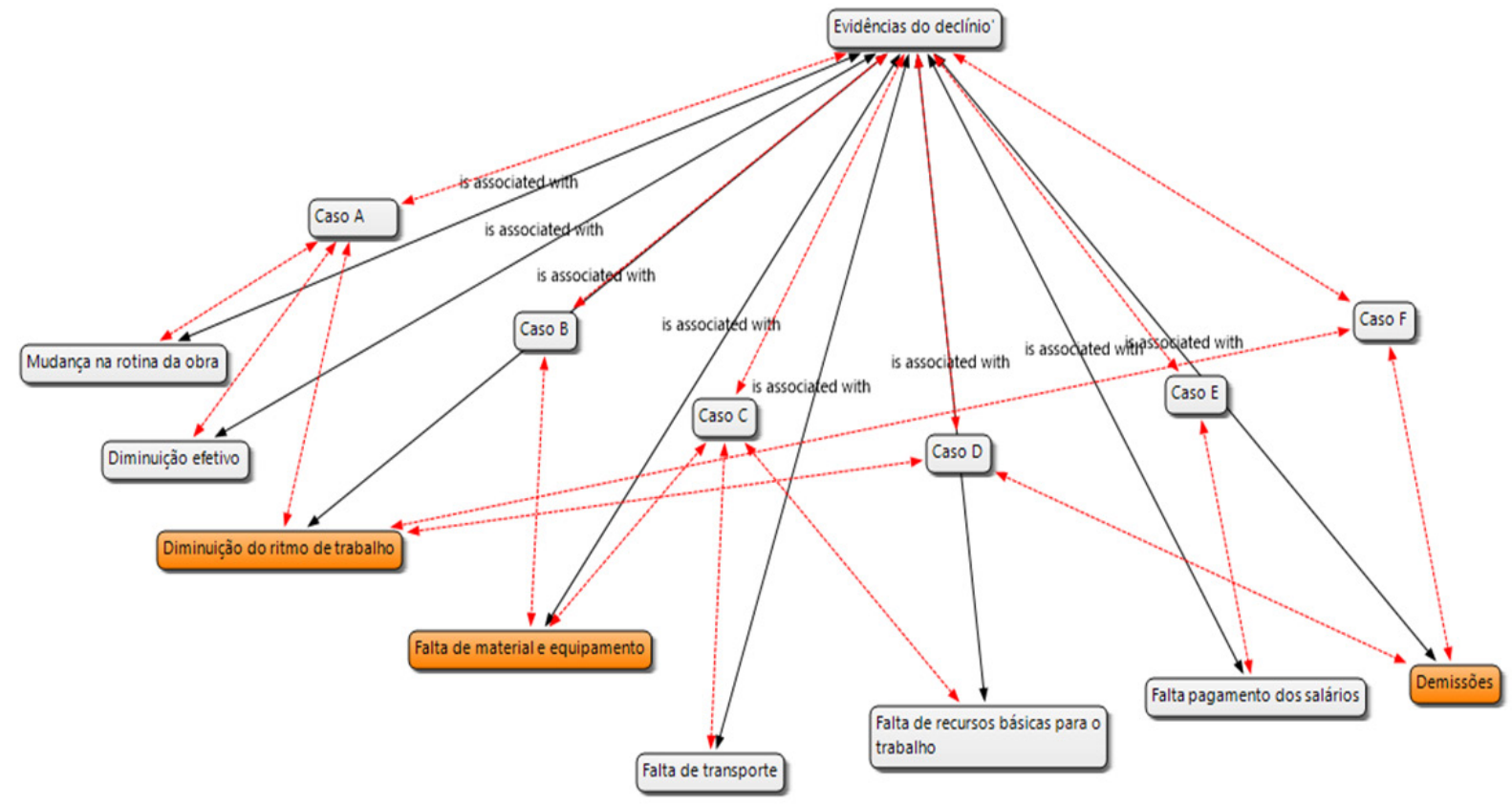

Fonte: Vasconcelos (2016).

A ausência de recurso financeiro aparece como uma evidência básica de declínio, a partir da qual outros traços também são indicados, como diminuição do ritmo de trabalho $(A, D, F)$ e do efetivo (A), falta de transporte, equipamentos, recursos básicos para o trabalho, e de pagamentos (B, C, E). A inabilidade em lidar com as condições desfavoráveis da organização declinante resulta na perda de controle e de recursos, ressaltando o aspecto financeiro como o principal fator de declínio (REGO; CUNHA, 2003). A mudança ambiental desfavorável, estrutura ineficiente e estratégias frágeis apresentam-se como motivos, a partir dos quais os sintomas, como a escassez de recursos, indicam a limitação das possibilidades de recuperação (MADEIRA, 2003). 
Figura 3 - Esquema dos sintomas de declínio organizacional

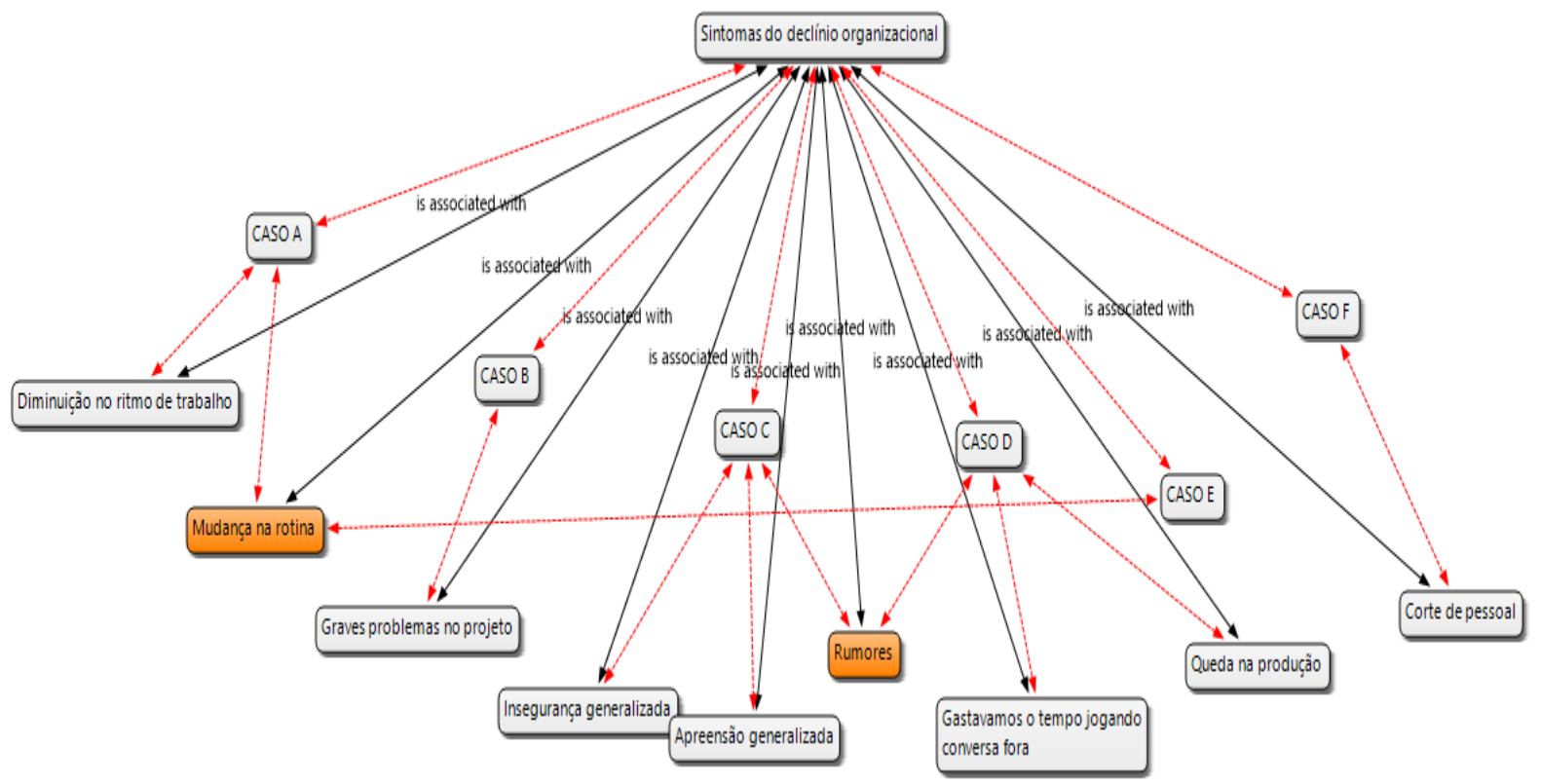

Fonte: Vasconcelos (2016).

Mckernan (2002) classifica os sintomas do declínio em físicos, gerenciais, comportamentais e financeiros. A, D, e E expressam as mudanças na rotina, com diminuição do ritmo de trabalho e queda na produção, que B reitera minuciosamente e define como graves problemas no projeto. As falas expressam problemas gerenciais e financeiros, evidenciando que o processo de declínio começa com as alterações no ambiente e/ou nas características da organização. O fenômeno de declínio pressupõe que a degradação da empresa tem início com sintomas primários que se referem à deterioração do desempenho, mas a degradação se oficializa com a crise financeira.

Tendo-se o entendimento de que a rede de rumores surge como um sintoma do período, apresentando-se como difícil e até traumático para os atores, nesse momento, novamente aparece o corte de pessoal (F), a queda na produção (D) e a redução no ritmo de trabalho (A). D’Aveni (1989) reconhece e associa a redução de recursos humanos ao declínio, demissões que tendem a acarretar danos psicológicos aos que ficam, como o destaque dado por $\mathrm{C}$ ao relatar insegurança e apreensão generalizada

Por outro lado, quando se trata das consequências do declínio, pode-se observar uma significativa diferença na densidade e complexidade do esquema. Rousseau (2001), ao discutir a complexidade dos esquemas, argumenta que quanto maior a matriz de ligação mais complexo tende a ser o esquema. A partir da análise das cognições a respeito das consequências, pressupõe-se que a complexidade é formada pela mobilização de diversos conteúdos, motivados pela ameaça de desemprego. 
Figura 4 - Esquema das consequências do declínio organizacional

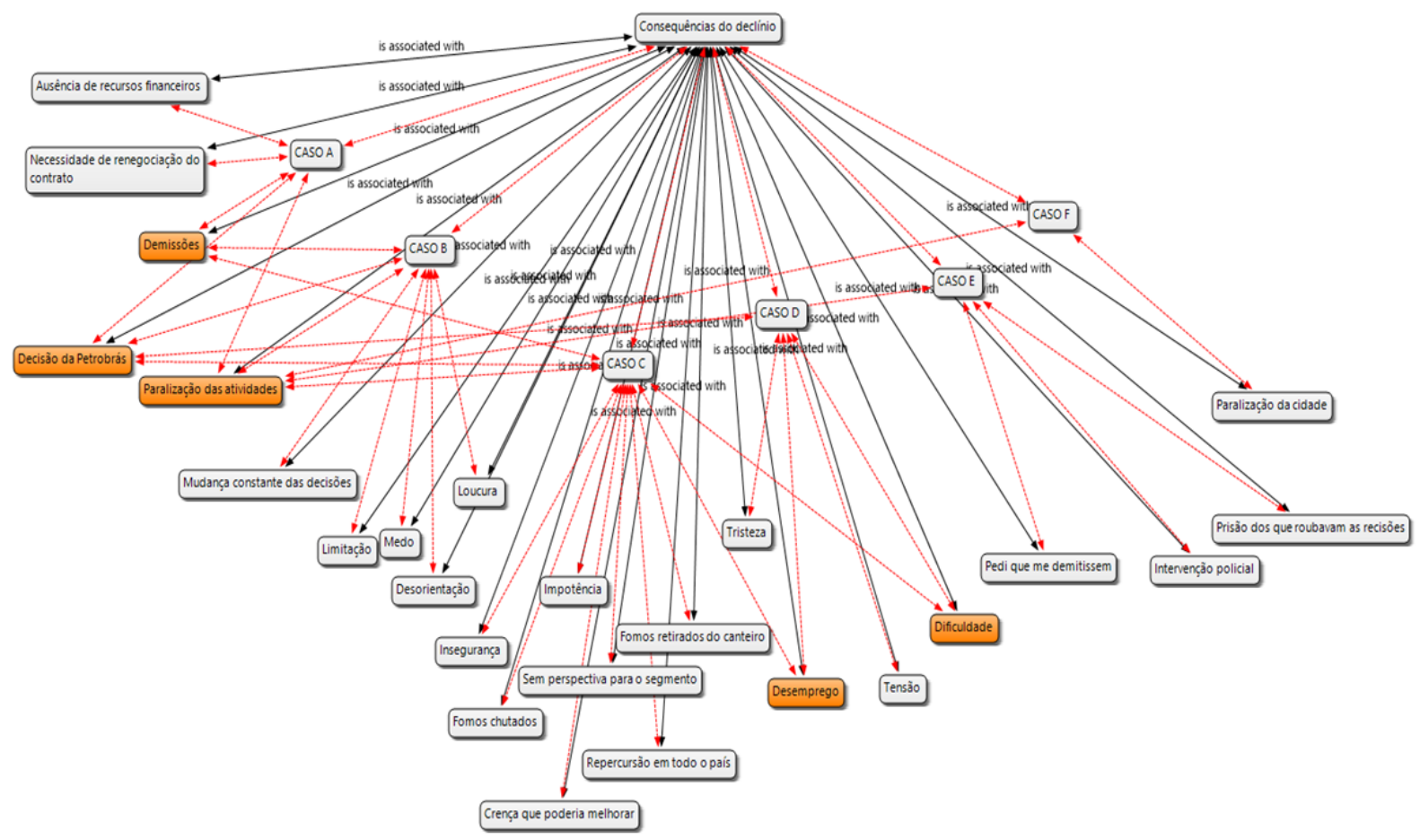

Fonte: Vasconcelos (2016).

Para os atores, o declínio acarreta demissões ( $A, B$ e $C$ ), desemprego e dificuldades ( $C$ e D) como nestes apontamentos. $B$ destaca uma mudança constante nas decisões e $C$ a falta de perspectiva. Em relação ao aspecto social, $\mathrm{F}$ relata a paralisação também da cidade. Madeira (2003) argumenta que algumas características são consequências potencializadas do declínio, como os conflitos e o enfraquecimento da moral.

Mas, nesse sentido, também surgem os gestores e a gestão como um fator fundamental tanto para facilitar como para limitar a codificação das informações entre os atores. Madeira (2003) sinaliza a tendência da gestão em negar o declínio e até a crise financeira, o que permite compreender, portanto, a ausência de feedback dos gestores sentida pelos atores. A paralisação do projeto organizacional UFN III é identificada como consequência do declínio, e assim citada por todos os atores $(A, B, C, D, E$ e $F)$; e relacionada na maioria dos casos $(A, B, C$ e $D)$ à decisão da Petrobrás.

Assim, sem dúvida, despontam os relatos sobre as consequências do declínio dos atores que se mantiveram até o final, ou seja, até a paralisação do projeto. As denominações empregadas e as justificativas deixam mais explícitos os efeitos da situação, mudança constante nas decisões (B), medo (B), loucura (B), desorientação (B), insegurança (C), impotência (C), falta de perspectiva (C), tensão (D), tristeza (D). Esses dados corroboram os achados de Caldas (1998, p. 94), que descreve esse processo como a "síndrome dos sobreviventes, envolvendo sentimentos fortes e ambivalentes de dor, medo e culpa, mas também de alívio e excitação, daqueles que mantêm seus empregos após enxugamentos".

\subsection{Pós-declínio}

O pós-declínio também se relaciona ao desligamento do trabalhador do projeto organiza- 
cional da UFN III e as perspectivas e realizações quanto ao mercado de trabalho. A interpretação cognitiva do evento desperta emoções que influenciam a maneira como esse trabalhador lida com a perda do emprego, como estabelece novas rotinas, pois os esquemas cognitivos selecionam as informações salientes e determinam como serão interpretadas

A despeito das informações sobre mercado em que os atores buscariam se reinserir, Ganz (2015) oferece um panorama, descrevendo a transformação radical pela qual vem passando o país desde o primeiro semestre de 2015. Alterações significativas com indicadores que apontam para diminuição da perspectiva econômica, aumento do desemprego e da informalidade e queda de renda. Esse cenário, com características opostas às observadas na última década, volta a promover a diminuição dos salários pagos aos novos contratados no país; o drama do desemprego tem enredamento com desalento, sofrimento, luta e desespero pelas dificuldades causadas aos trabalhadores e suas famílias. Essa situação que surge explicitamente no discurso dos trabalhadores.

Nesse sentido, os conteúdos partilhados entre os atores revelam caracteristicamente as mudanças de vida, evidenciando que a constituição e a dinâmica da realidade interna que orienta suas ações têm do ambiente social uma significativa contribuição.

Figura 5 - Esquema das mudanças de vida, no pós-declínio

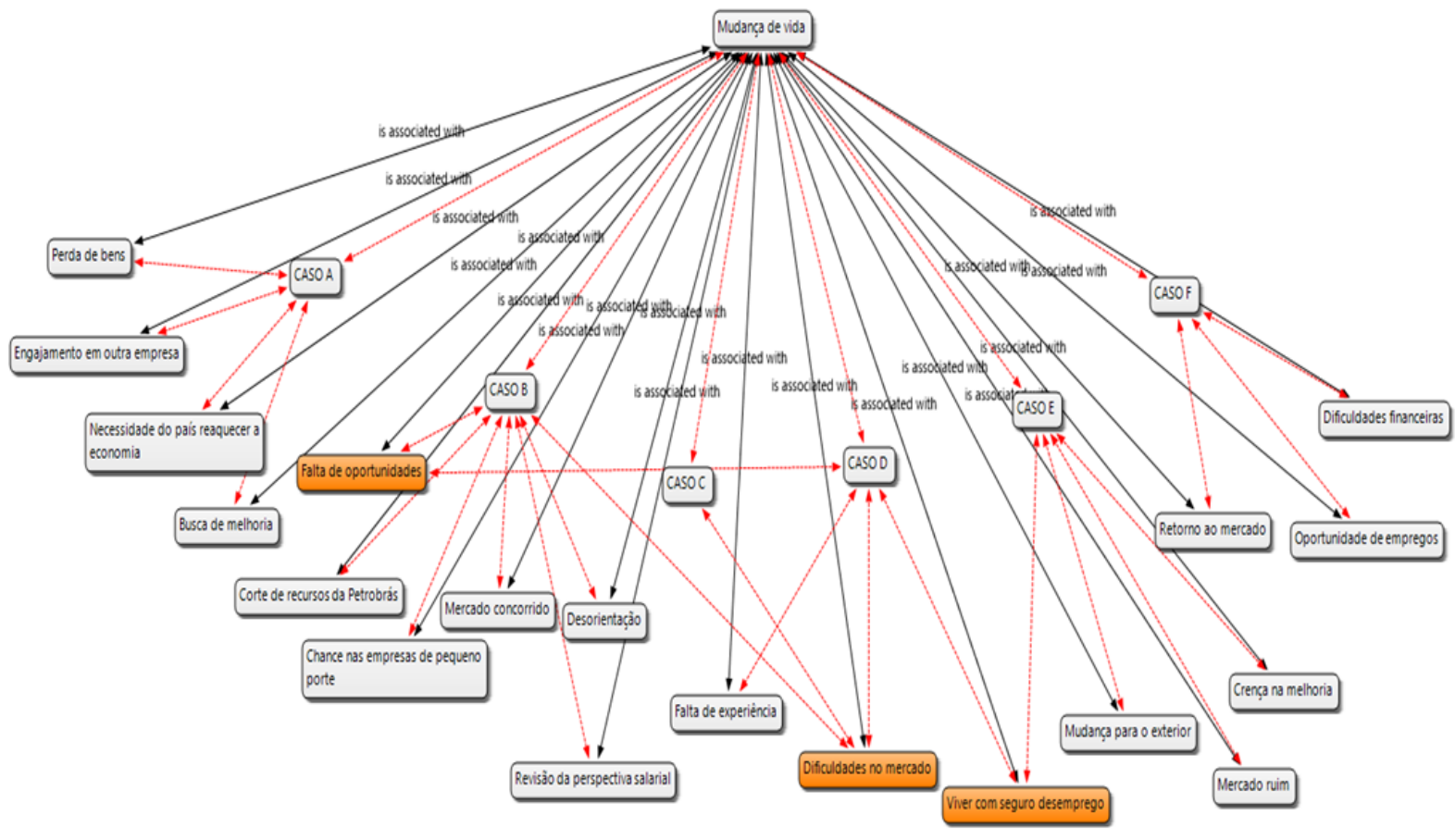

Fonte: Vasconcelos (2016).

Após o desligamento, A discorre sobre as perdas de bens, relata sua inserção em uma nova empresa (com uma remuneração menor) e atribui isso à situação atual do país, mas garante que vai continuar a busca por melhorias em sua vida profissional e econômica; C, embora também recolocado, expressa somente as dificuldades; $D$ aponta as dificuldades, mas ressalta o respaldo do seguro desemprego à sua sobrevivência; e $F$ cita as dificuldades financeiras que existiram após o declínio, mas em seguida já coloca as oportunidades existentes. Os dados fornecem evidências claras de mudanças na compreensão; esse aprendizado com associações sociais a partir 
do ambiente pode levar à eliminação de conceitos assumidos anteriormente e à projeção de outros. Pode-se presumir, a partir dos dados, que as dificuldades vividas são consideradas como contribuições a modificações ou pequenas mudanças às interpretações de mercado.

Os conteúdos que ilustram a visão do mercado que irão enfrentar, apresentam-se associados às dificuldades políticas e econômicas do país $(A, E, B)$, com obstáculos como a concorrência e a falta de experiência (D). Torna-se evidente que o modo como significam a experiência depende de suas características pessoais, sociais e da forma como seus conceitos estão inter-relacionados, e dos pressupostos que dão sentido à realidade que lhes permite lidar com as mudanças.

A categorização social é sempre o passo inicial para formação das impressões, que podem extrapolar esse conteúdo estereotípico, especialmente quando foge, em alguns aspectos, às expectativas iniciais ou quando for merecedor de uma atenção mais individualizada em função da relevância para o indivíduo. Caldas (1999) destaca como seguro afirmar que os indivíduos sofrem os impactos do desemprego e o avaliam subjetivamente, o que permite que se adaptem a sua forma, dependendo de suas condições pessoais, significativamente variadas e complexas. Buscar empresas e remunerações menores, assim como flexibilizar-se em relação aos cargos, surge como uma estratégia de enfrentamento à situação para reinserção. Embora B ainda esteja em situação de desemprego, ele define sua pretensão salarial menor do que na UFN III, e o trabalhador E pensa em ir para o exterior, em busca de emprego e de remuneração melhor.

Todas as características referentes à intenção de se inserir permanecem associadas ao mercado e corroboram com os argumentos já discutidos sobre a situação atual do país. Quanto às necessidades de os atores reduzirem suas expectativas atuais, especialmente as salariais, é importante destacar a ênfase depositada na crença da melhoria durante as entrevistas, o que dá uma conotação temporária à estratégia.

Ao caracterizar as mudanças que demarcam a visão dos atores sobre o mundo contemporâneo do trabalho, faz-se necessário considerar o sofrimento para aqueles que não conseguem reempregar-se, como B, que relata desorientação desde o desfecho de declínio, mas complementarmente para aqueles que trabalham também, pela frustração ou insatisfação quanto à realidade atual. Para Souza (2007, p. 45), são "os esquemas que ajudam as pessoas a gerenciarem, de forma simples e efetiva, as complexas características do ambiente social e do trabalho".

Os esquemas reduzem a demanda do processamento de informações associadas às atividades sociais, fornecendo um sistema de conhecimento preparado para interpretar e armazenar informações acerca de outras situações. Quando se fala em mudança, há também a identificação de que novas informações não se encaixem exatamente nas expectativas anteriores. Axelrod (2014) denomina como equilíbrio esquemático um conjunto de crenças equilibradas sobre determinado objeto, situação ou evento.

Mais formalmente, o equilíbrio pode ser definido em termos de um conjunto de objetos e as relações entre eles. O esquema é capaz de modificar algumas das informações à luz de sua antiga interpretação, e o restante da informação é incorporado. Isso permite a mudança de crenças acerca do conjunto. As mudanças são correções ou distorções dependendo da precisão da nova interpretação e da especificação, ou seja, a especificação do caso dado ao indivíduo e incorporado ao esquema permite previsões, que podem ser úteis para a decisão, mas, dependendo de como foi constituída, pode não ser um guia adequado para o comportamento (AXELROD, 2014).

Enquanto esquemas surgem para facilitar a organização das informações e o sentido do mundo pelos indivíduos, eles também podem deixá-los cegos para as características do mundo 
que ameaçam a validade desses esquemas ou operar fora do seu alcance. Demonstra-se, assim, que existem implicações importantes para expandir a compreensão dos esquemas e do sentido nas organizações. Mas é importante ressaltar que pressupostos fundamentais sobre a natureza do mundo social podem ser alterados pelos processos e estruturas cognitivas.

\section{CONSIDERAÇÕES FINAIS}

O estudo chama a atenção para o fenômeno de declínio organizacional e busca descrever como seis trabalhadores o significam a partir de suas experiências na UFN III. Nesse caso, pode-se definir declínio como um processo complexo que leva à paralisação do projeto organizacional por um conjunto de variáveis ambientais, estruturais e comportamentais, que foi proposto conhecer a partir da experiência de seis trabalhadores.

A articulação entre os seis casos permitiu a identificação de uma estrutura que evidencia a subjetividade dos esquemas, mas também demonstra similaridades a partir do compartilhamento de conceitos e ideias-chave entre os atores. Os relatos revelam que o insucesso (declínio) do projeto organizacional está para além da dimensão financeira e integra questões políticas, sociais e morais. O reconhecimento desses fatores não permitiu a elaboração de estratégias de recuperação, corroborado pela noção anterior de que nada seria suficiente para desequilibrar ou estagnar uma obra da Petrobrás no Brasil, especificamente do porte da UFN III, e que acabou por acontecer.

O declínio da UFN III, para os trabalhadores, encontra-se relacionado predominantemente aos fatores macroambientais, como a Petrobrás e a operação Lava Jato, devido à corrupção identificada pelo superfaturamento, falta de planejamento, entre outras questões. Ainda no que diz respeito ao declínio, os atores reconhecem causas, evidências, sintomas e consequências; esses dados corroboram com Madeira (2003) no que se refere à percepção dos atores quanto às fases do declínio descritas pelo ator. Os impactos gerados pela situação vivida confirmam as informações descritas a respeito das consequências de declínio, assim como de outros processos/ fenômenos nos quais as demissões em massa ocorrem.

Percebe-se claramente, a partir do mapeamento cognitivo, que os esquemas mais complexos desse grupo são: o de consequências do declínio e o de pós-declínio. Constatação de que situações que tendem a mobilizar mais emoção apresentam esquemas mais complexos. Nesse sentido, também se torna relevante discutir a modificação de esquemas a partir de situações de crise e a incorporação de novas informações, pois, quanto mais estímulo e informações relevantes forem encontrados, mais complexo tende a ser o esquema.

O desenvolvimento de conhecimentos na forma de esquemas altamente elaborados, resultantes da incorporação de informações advindas de muitas experiências em uma determinada área de preocupação, é um exemplo de modificação de esquema. Uma consideração importante em relação a este estudo são as condições de vida e de trabalho na atualidade. De maneira geral, os trabalhadores demonstraram viver mudanças e enfrentar consequências decorrentes do processo de paralisação da UFN III e consequente desligamento; no entanto as situações atuais de desemprego e emprego merecem ser levadas em conta em novas investigações para que seja possível considerar com maior precisão outros fatores que podem interferir na constituição da percepção. Essa posição, contudo, parece corroborar com Bastos e Janissek (2014) quanto à argumentação de que estudos de mudanças nas representações cognitivas podem auxiliar na 
adaptação. Nesse sentido, considera-se que os resultados apontam caminhos que precisam ser mais bem explorados em pesquisas futuras, como o significado da experiência de trabalho e a mediação do status ocupacional (empregado e desempregado) e o auxílio da ressignificação cognitiva na recuperação dessas situações.

\section{REFERÊNCIAS}

AXELROD, R. Schema Theory: an information processing model of perception and cognition. American Political Science Review, Reino Unido, v. 67, n. 4, p. 1248-66, 2014.

BASTOS, A. V. B.; JANISSEK, J. Cognição nas organizações de trabalho. In: ZANELLI, J. C.; BORGES-ANDRADE, J. E.; BASTOS, A. V. B. (Org.). Psicologia organizações e trabalho no Brasil. Porto Alegre: Artmed, 2014. p. 203-43.

BASTOS, A. V. B; LOIOLA, E.; QUEIROZ, N. S.; SILVA, T. D. Conceito e perspectivas do estudo das organizações. In: ZANELLI, J. C.; BORGES-ANDRADE, J. E.; BASTOS, A. V. B. (Org.). Psicologia organizações e trabalho no Brasil. Porto Alegre: Artmed, 2014. p. 73-108.

BREAKWELL, G. M. et al. Métodos de pesquisa em Psicologia. Tradução de Felipe Rangel Elizalde. Porto Alegre: Artmed, 2010.

CALDAS, M. P. Demissão, plural e singular: um estudo sobre enxugamentos de pessoal no nível organizacional e sobre perda de emprego no nível individual. Orientador: Fernando C. Prestes Motta. 1998. 374 f. Tese (Doutorado em Administração) - Escola de Administração de Empresas de São Paulo, Fundação Getúlio Vargas, São Paulo, SP, 1998.

CALDAS, M. P. A demissão e alguns significados psicológicos da perda do emprego para o indivíduo. In: ENCONTRO NACIONAL DE PÓS-GRADUAÇÃO E PESQUISA EM ADMINISTRAÇÃO- ENANPAD, Curitiba, 1999. Anais [...]. Curitiba: ENANPAD, 1999. Disponível em: http://www.anpad.org.br/admin/pdf/enanpad1999rh-10.pdf. Acesso em: 25 maio 2017.

CARVALHO, K. L. Uma proposta para o diagnóstico do declínio organizacional. Orientador: Reinaldo Pacheco da Costa. 2013. 196f. Tese (Doutorado em Engenharia de Produção) - Escola Politécnica, Universidade de São Paulo, São Paulo, SP, 2013. Disponível em: http://www.teses.usp.br/teses/disponiveis/3/3136/ tde-07062014-121156/. Acesso em: 23 dez. 2015. DOI: 10.11606/T.3.2013.tde-07062014-121156.

D'AVENI, R. A. The Aftermath of Organizational Decline: a longitudinal study of the strategic and managerial characteristics of declining firms. The Academy of Management Journal, Estados Unidos, v. 32, n. 3, p. 577-605, 1989.

EGGERS, J. P.; KAPLAN, S. Cognition and Renewal: comparing CEO and Organizational Effects on Incumbent Adaptation to Technical Change. Organization Science, Estados Unidos, v. 20, n. 2, p. 461-77, 2009. Disponível em: http://dx.doi.org/10.1287/orsc.1080.0401. Acesso em: 26 fev. 2016.

GANZ, L. C. Desafios para o crescimento e o emprego. Estudos Avançados, São Paulo, v. 29, n. 85, p. 2133, 2015. Disponível em: http://www.scielo.br/scielo.php?script=sci_arttext\&pid=S0103401420150003 00003\&lng=en\&nrm=iso. Acesso em: 20 out. 2016. DOI: 10.1590/S0103-40142015008500003.

HOWARD, J. A.; RENFROW, D. G. Social Cognition. In: DELAMATER, J. (Ed.). Handbook of Social Psychology. Nova Iorque: Kluwer Academic/Plenum Publishers, p.259-281, 2003.

LABIANCA, G.; GRAY B.; BRASS, D. J. A grounded model of organizational schema change during empowerment. Organization Science, Estados Unidos, v. 11, n. 2, p. 235-57, 2000. 
MADEIRA, P. Falência ou recuperação empresarial como resultado do declínio organizacional: uma estrutura conceptual explicativa. GESTIN: Revista de Escola Superior de Gestão, Portugal, v. 2, n. 2, p. 191-206, 2003. Disponível em: http://repositorio.ipcb.pt/bitstream/10400.11/235/1/PauloMadeira191206Documento\%20do\%20Microsoft\%200ffice\%20Word.pdf. Acesso em: 23 dez. 2015.

MCKERNAN, S. M. The impact of microcredit programs on self-employment profits: do noncredit program aspects matter? Review of Economics and Statistics, Estados Unidos, v. 84, n. 1, p. 93-115, 2002.

MOHAMMED, S.; KLIMOSKI, R.; RENTSCH, J. R. The Measurement of team mental models: we have no shared schema. Organizational Research Methods, Estados Unidos, v. 3, n. 123, p. 123-65, 2000.

NOBRE, F. S.; TOBIAS, A. M.; WALKER, D. S. Uma visão da empresa baseada em habilidades: contextos estratégicos e contingenciais. Revista de Administração Contemporânea, Curitiba, v. 15, n. 3, p.413-32, 2011. Disponível em: http://www.anpad.org.br/rac. Acesso em: 20 jan. 2016.

ORGANIZAÇÃO PARA A COOPERAÇÃO E DESENVOLVIMENTO ECONÔMICO. Agricultura brasileira: perspectivas e desafios - OCDEFAO. OCDE, 2015. Disponível em: https://www.fao.org.br/download/ PA20142015CB.pdf. Acesso em: 25 nov. 2015.

REGO, A.; CUNHA, M. A essência da liderança. Lisboa: Editora RH, 2003.

RIEG, D. L.; ARAUJO FILHO, T. Mapas cognitivos como ferramenta de estruturação e resolução de problemas: o caso da Pró-Reitoria de Extensão da UFSCar. Gestão e Produção, São Carlos, v. 10, n. 2, p. 145-62, 2003. Disponível em: http://www.scielo.br/scielo.php?script=sci_arttext\&pid=S0104-530X2003000200003\&ln $\mathrm{g}=\mathrm{en} \& \mathrm{nrm}=$ iso. Acesso em: 11 fev. 2016. DOI: 10.1590/S0104-530X2003000200003

RIOS, M. C.; LULA, A. M.; AMARAL, N. A.; BASTOS, A. V. B. Contratos psicológicos e comprometimento: o mapeamento cognitivo dos construtos junto a profissionais de RH. Acta Científica, São Paulo, v. 1, n. 16, p. 9-24, 2009.

ROUSSEAU, D. M. Schema, promise and mutuality: the building blocks of the psychological contract. Journal of occupational and organizational psychology, Inglaterra, v. 74, n. 4, p. 511-41, 2001.

SALLES, L. F. Como as empresas brasileiras da indústria têxtil lidam com o declínio? Um estudo multicaso das ações estratégicas. Orientador: Fernando Antonio Ribeiro Serra. 2015. 99f. Dissertação (Mestrado em Administração) - Universidade Nove de Julho, São Paulo, SP, 2015.

SERRA, F.; FERREIRA, M.; ALMEIDA, M. Organizational decline: a yet largely neglected topic in organizacional studies. Management Research: Journal Of The Iberoamerican Academy Of Management, Reino Unido, v. 11, n. 2, p. 133-56, 2013.

SOUZA, J. J. Teoria implícita de organização inovadora em empresas com padrões diferenciados de adoção de práticas de gestão. Orientador: Antonio Virgílio Bittencourt Bastos. 2007. 274f. Tese (Doutorado em Administração) - Núcleo de Pós-Graduação em Administração, Universidade Federal da Bahia, Salvador, BA, 2007.

VASCONCELOS, E. F, COSTA, M. A construção social de conhecimentos, crenças e atitudes nas organizações de trabalho. In: ALMEIDA, L. P. Políticas públicas, cultura e produções sociais. Campo Grande, MS: UCDB, 2016.

VASCONCELOS, E. F. Declínio do projeto organizacional UFN III: explorando o significado da experiência entre os atores. 2016. Orientador: Marcio Luis Costa. 222f. Tese (Doutorado em Psicologia) - Programa de Pós-Graduação em Psicologia, Universidade Católica Dom Bosco, Campo Grande, 2016. 
WILDMAN, J. L.; SALAS, E.; SCOTT, C. P. R. Measuring Cognition in Teams: A Cross-Domain Review. Human Factors, Estados Unidos, v. 20, n. 10, p.1-31, 2013.

\section{Sobre os autores:}

Eveli Freire Vasconcelos: Doutorado, mestrado e graduação em Psicologia pela Universidade Católica Dom Bosco (UCDB). Docente e supervisora de estágio no Curso de Graduação em Psicologia. Experiência em Psicologia, Organizações e Trabalho, atuando principalmente em temas da área: gestão de pessoas, comportamento organizacional. E-mail: evelivasconcelos@yahoo.com.br, Orcid: http://orcid.org/0000-0001-5140-760X

Antonio Virgílio Bittencourt Bastos: Doutorado em Psicologia pela Universidade de Brasília, com concentração em Psicologia Organizacional e do Trabalho. Mestrado em Educação e Graduação em Psicologia pela Universidade Federal da Bahia (UFBA). Professor titular de Psicologia Social das Organizações, no Instituto de Psicologia da UFBA. Coordenador da Área de Psicologia da CAPES e membro, no INEP, da Comissão de Psicologia para o ENADE. Pesquisador I-A do $\mathrm{CNPq}$, atuando principalmente em temas da área de Comportamento Organizacional. E-mail: antoniovirgiliobastos@gmail.com, Orcid: http://orcid.org/0000-0002-1322-5749 
